\title{
Bradykinin stimulates IL-6 and IL-8 production by human lung fibroblasts through ERK- and p38 MAPK-dependent mechanisms
}

\author{
R. Hayashi, N. Yamashita, S. Matsui, T. Fujita, J. Araya, K. Sassa, N. Arai, Y. Yoshida, \\ T. Kashii, M. Maruyama, E. Sugiyama, M. Kobayashi
}

Bradykinin stimulates IL-6 and IL-8 production by human lung fibroblasts through ERKand p38 MAPK-dependent mechanisms. R. Hayashi, N. Yamashita, S. Matsui, T. Fujita, J. Araya, K. Sassa, N. Arai, Y. Yoshida, T. Kashii, M. Maruyama, E. Sugiyama, M. Kobayashi. (C) ERS Journals Ltd 2000.

ABSTRACT: Bradykinin (BK) is a major kinin with well-documented pharmacological properties including vascular leakage and induction of a variety of cytokines. However, the intracellular signalling mechanisms by which BK induced proinflammatory cytokine production have not been fully elucidated. This study investigated the role of the extracellular signal-regulated protein kinase 1/2 (ERK 1/2) and p38 mitogen-activated protein kinase (p38 MAPK) in the BK-induced interleukin (IL)-6 and IL-8 production by human lung fibroblasts.

Lung fibroblasts were stimulated with $B K$ in the presence or in the absence of PD98059, a specific MAPK/ERK kinase-1 inhibitor, or SB203580, a specific p38 MAPK inhibitor, and IL-6 or IL-8 production and their gene expression was examined. BK-induced ERK $1 / 2$ or p38 MAPK phosphorylation was also analysed by Western blot analysis.

BK at nanomolar concentrations stimulated lung fibroblasts to produce IL-6 and IL-8 along with increased ERK $1 / 2$ and $\mathbf{p 3 8}$ MAPK phosphorylation. BK-induced IL6 and IL-8 synthesis was inhibited by a B2-type BK receptor antagonist. Furthermore, PD98059 or SB203580 significantly suppressed BK-induced IL-6 and IL-8 production and their gene expression.

These results indicate that bradykinin-induced interleukin- 6 and interleukin-8 production are at least partly mediated through the extracellular signal-related protein kinase $1 / 2$ and p38 mitogen-activated protein kinase pathway-dependent activation in human lung fibroblasts, and suggest that bradykinin appears to be involved in the inflammatory reaction leading to acute lung injury through stimulating interleukin-6 and interleukin-8 production by lung fibroblasts.

Eur Respir J 2000; 16: 452-458.
First Dept of Internal Medicine, Toyama Medical and Pharmaceutical University, Toyama, Japan.

Correspondence: N. Yamashita

First Dept of Internal Medicine

Toyama Medical and Pharmaceutical University

2630 Sugitani

Toyama 930-0194

Japan

Fax: 81764345025

Keywords: Bradykinin

interleukin-6

interleukin- 8

lung fibroblasts

protein kinase

Received: November 221999

Accepted after revision May 52000
Bradykinin (BK) is a pluripotent nonapeptide that is generated from kininogens by the action of plasma and tissue kallikreins. It has been postulated that the kallikreinkinin system is important in the pathophysiology of acute lung injury, acute (adult) respiratory distress syndrome (ARDS) and multiple organ failure. Experimental endotoxin shock, bacterial sepsis, and ARDS decrease kininogen and prekallikrein levels, and increase kallikrein activity and levels of kinins [1-5]. Furthermore, hypoxia is known to decrease lung angiotensin-converting enzyme (ACE) activity. For example, there is severe depression of lung $\mathrm{ACE}$ activity following acute lung injury, and the serum ACE level decreases in sepsis-induced ARDS in humans $[6,7]$. Thus, hypoxia may decrease BK degradation in the lung of ARDS patients, thereby potentiating the harmful effects of the peptide. These findings are important in considering the role of BK and related kinins in the generation and continuation of tissue injury and inflammation of the lung.

In the alveolar interstitium, the principal cell type is the fibroblast, which plays an integral role in repairing damaged lung tissue. Lung fibroblasts have the potential to induce inflammation in the alveolar interstitium by releasing proinflammatory cytokines in response to a variety of stimuli [8-10]. Recently, it has been reported that BK stimulated human lung fibroblasts to produce interleukin (IL)- 8 by increasing its gene expression [11]. BK also increases the production of IL-1, IL-2, and IL-6 from isolated guinea pig lung strips [12], and IL-1 from cultured human lung fibroblasts [13]. These data suggest that BK may be involved in the control of the inflammatory reaction associated with interstitial lung disorders through proinflammatory cytokines production by lung fibroblasts.

It has also been reported that the stimulatory effect of BK on IL-8 production by lung fibroblasts was mediated, at least in part, via the protein kinase $\mathrm{C}$ (PKC) dependent activation pathway. However, the intracellular signalling mechanisms by which BK-induced proinflammatory cytokine production by lung fibroblasts have not been fully elucidated. The present studies were designed to delineate the signalling pathways involved in BK-induced IL-6 and IL-8 production by human lung fibroblasts.

Mitogen-activated protein kinases (MAPK) have been implicated in a number of signalling events that are potentially important in the inflammatory response. Extracellular signal-regulated protein kinase 1/2 (ERK 1/2) pathways are activated predominantly by growth factors 
[14], but activation by IL-1 or tumour necrosis factor (TNF) has also been demonstrated $[15,16]$. In addition, Jun amino terminal kinase (JNK) and p38 MAPK are activated by inflammatory cytokines and cellular stress such as heat shock or ultraviolet light $[17,18]$. Therefore, the ERK $1 / 2$ and p38 MAPK involvement in BK-induced IL-6 and IL-8 production in human lung fibroblasts was investigated.

In this study, it was found that BK stimulates human lung fibroblasts to produce IL-6 and IL-8 along with increased ERK 1/2 and p38 MAPK phosphorylation, and that PD98059, a specific MAPK/ERK kinase-1 (MEK1) inhibitor, and SB203580, a specific p38 MAPK inhibitor, suppress BK-induced IL-6 and IL-8 production and their gene expression. These data suggest that ERK 1/2 and p38 MAPK are necessary for the BK-induced IL-6 and IL-8 production in human lung fibroblasts.

\section{Materials and methods}

\section{Reagents}

BK, B1-receptor antagonist des-Arg ${ }^{9}-\left(\mathrm{Leu}^{3}\right)$-Bradykinin, and B2-receptor antagonist (D-Arg ${ }^{0}, \mathrm{Hyp}^{3}$, $\mathrm{Thi}^{5}$,

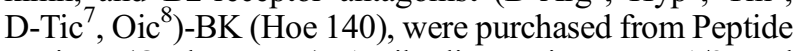
Institute (Osaka, Japan). Antibodies against ERK 1/2, and phospho-ERK 1/2 (Thr/Tyr), p38 MAPK, and phosphop38 MAPK ( $\operatorname{Thr}^{180} / \mathrm{Tyr}^{182}$ ) were purchased from NEB (Beverly, MA, USA). SB203580, a p38 MAPK specific inhibitor, and PD98059, which selectively inhibits MEK-1 and suppresses ERK activation, were obtained from Calbiochem (La Jolla, CA, USA). Dulbecco's modified Eagle's medium (DMEM) and phosphate buffered saline (PBS(-)) were purchased from Nissui (Tokyo, Japan).

\section{Cell preparation and culture}

Human lung tissues were obtained from lungs of patients undergoing lobectomy because of lung cancer. The participants all had normal lung function and used no medication. Normal parts of the tissue were washed with PBS, and pleural tissue and bronchi were removed after resection. Primary cultures of human lung fibroblasts were prepared as described elsewhere [19] with a few modifications [11]. Briefly, specimens were cut into small pieces and digested with $0.5-1 \mu \mathrm{g} \cdot \mathrm{mL}^{-1}$ of clostridium collagenase (Wako Pure Chemical Industries, Osaka, Japan) and 5-10 mg. $\mathrm{mL}^{-1}$ of deoxyribonuclease 1 (Sigma St. Louis, MO, USA) for $2 \mathrm{~h}$. After digestion, the single cells were filtered through sterile gauze, washed three times with DMEM and filtered through nylon mesh (FALCON Franklin Lakes, NJ, USA). The cells were resuspended in complete medium (DMEM supplemented with $10 \%$ heat-inactivated foetal calf serum (FCS) (ICN Biomedicals, Australia), $50 \mathrm{U} \cdot \mathrm{mL}^{-1}$ penicillin G, 50 $\mu \mathrm{g} \cdot \mathrm{mL}^{-1}$ streptomycin (Gibco, Grand Island, NY, USA), and $2 \mathrm{mM}$ L-glutamine (ICN)). The cells were cultured overnight to allow them to adhere to a plastic dish. The dish was washed to remove nonadherent cells. Fibroblasts after 3-7 passages were used as human lung fibroblasts, and grown to confluence at $37^{\circ} \mathrm{C}$ in humidified $5 \% \mathrm{CO}_{2}$ in complete medium.

\section{Measurement of interleukin-6 and -8}

Immunoreactive IL-6 and IL-8 were measured using an enzyme linked immunosorbent assay (ELISA) kit (Central Laboratory of the Netherlands Red Cross Blood Transfusion Service, Amsterdam, the Netherlands). Lung fibroblasts were treated with trypsin (Gibco) and plated at a density of $1 \times 10^{5}$ cells per well, in 24-well flat-bottom plates. These cells were cultured with $\mathrm{BK}$ in the presence, or absence, of various reagents for $24 \mathrm{~h}$ in serum-free DMEM. PD98059 and SB203580 were added $1 \mathrm{~h}$ before stimulation with BK. Cell-free culture supernatants were collected and stored at $-20^{\circ} \mathrm{C}$ until IL- 6 and IL- 8 were assayed according to the manufacturer's instructions. Each assay detected as little as 5-7 $\mathrm{pg} \cdot \mathrm{mL}^{-1}$ of cytokine.

\section{Northern blot analysis}

Lung fibroblasts were seeded into $10-\mathrm{cm}$ culture dishes and stimulated with varying concentrations of BK. Total cellular ribonucleic acid (RNA) in the treated cells was extracted by acid guanidium thiocyanate-phenol-chloroform method using ISOGEN (Nippon Gene, Tokyo, Japan), and Northern blot analysis was carried out as previously described $[11,20]$. Twenty micrograms of total RNA was size-fractionated by electrophoresis through $1 \%$ agarose $/ 17 \%$ formaldehyde gels, and transferred to nylon membranes (Ammersham, Oakville, Canada). The 440 bp complementary deoxyribonucleic acid (DNA) (cDNA) of human IL-6, the $750 \mathrm{bp}$ cDNA of human IL-8, and $1.0 \mathrm{~kb}$ cDNA of human reduced glyceraldehyde phosphate dehydrogenase (GAPDH) inserted into pBluescript II SK+ were used as probes. These probes were labelled with digoxigenin dUTP by using a nonradioactive (DNA)-labelling and detection kit (Boehringer Mannheim, Mannheim, Germany). The intensity of the band was analysed by National Institute of Health Image 1.59 program.

\section{Western blot analysis}

Lung fibroblasts were cultured to confluence in 6-cm dishes. The complete medium was exchanged with fresh serum-free medium. The cells were incubated with BK for various times and washed twice in cold PBS(-). The cells were lysed in the cell solubililzing buffer $(10 \mathrm{mM}$ tris hydroxymethyl/amino methane (Tris), $\mathrm{pH} 7.4,1 \%$ Nonidet P-40 (nacalai tesque, Kyoto, Japan), $150 \mathrm{mM} \mathrm{NaCl}, 1 \mathrm{mM}$ ethylene glycol tetra acetic acid (EGTA), $1 \mathrm{mM}$ ethylene diamine tetra acetic acid (EDTA), $0.2 \mathrm{mM}$ phenylmethylsulphonyl fluoride (PMSF), $0.2 \mathrm{mM}$ sodium orthovanadate). After $10 \mathrm{~min}$ on ice, the cell lysate was centrifuged at $4{ }^{\circ} \mathrm{C}$ for $10 \mathrm{~min}$ to remove the insoluble materials and the supernatant was boiled with SDS sample buffer. The cell lysate was separated by $10 \%$ sodium dodecyl sulphatepolyacrylamide gel electrophoresis (SDS-PAGE) and transferred onto Immobilon-P membranes (Millipore, Bedford, MA, USA) in a Trans-Blot cell apparatus (Bio-Rad Laboratories, Hercules, CA, USA). Blotting with anti-ERK 1/ 2, anti-phospho-ERK 1/2, anti-p38 MAPK, and antiphospho-p38 MAPK was performed for over night at $4{ }^{\circ} \mathrm{C}$ (1/1000 dilution). Blots were then washed and incubated 
with a 1/2000 dilution of donkey anti-rabbit immunoglobulin antibody conjugated with horseradish peroxidase (Amersham, Buchinghamshire, UK). Binding of secondary antibody was detected with chemiluminescence reagents according to the manufacture's protocol (NEB).

\section{Statistical analysis}

All assays were performed in triplicate. The data were expressed as mean \pm SD. Differences between two groups were compared by Student's t-test. A p-value $<0.05$ was considered as statistically significant.

\section{Results}

Effect of bradykinin on the production of interleukin-6 -8 by lung fibroblasts

Lung fibroblasts were incubated for $24 \mathrm{~h}$ with increasing amounts of BK, and IL-6 and IL-8 were measured in the supernatants. As shown in figure 1a, lung fibroblasts produced trace amounts of IL- 6 and IL- 8 without stimuli. BK stimulated lung fibroblasts to produce IL-6 and IL-8 in a dose-dependent manner. After lung fibroblasts were
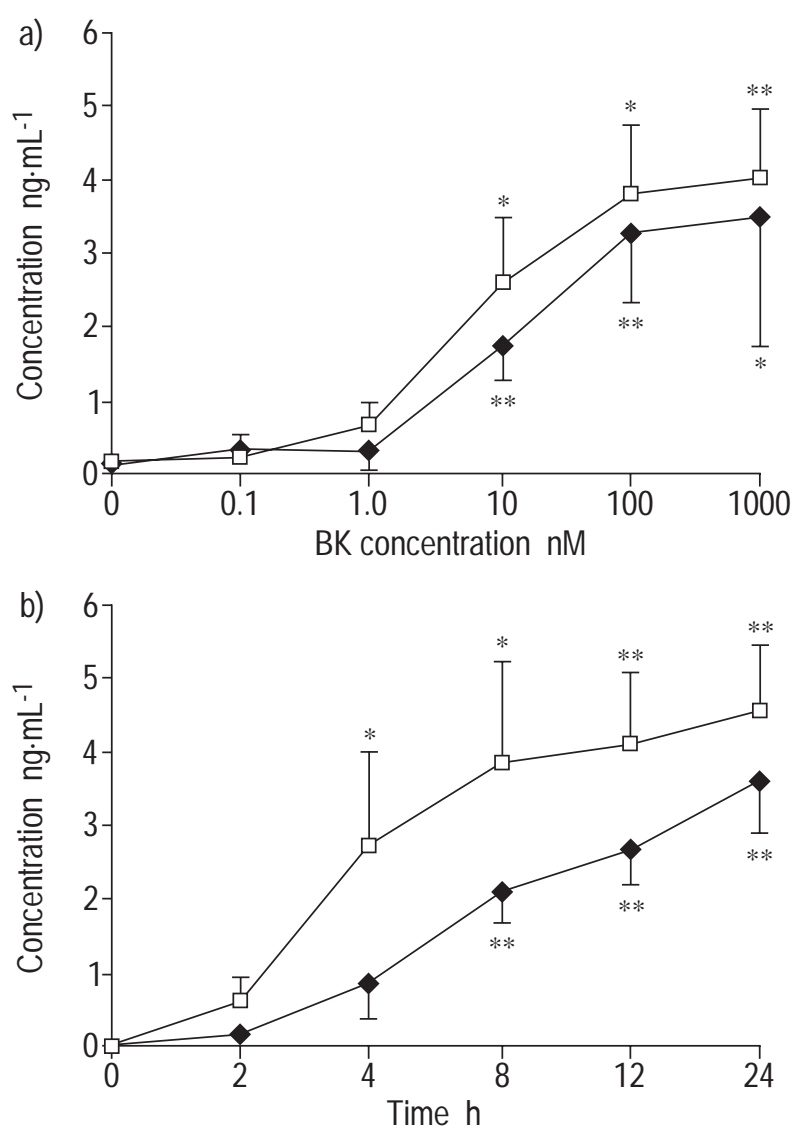

Fig. 1. - Effect of bradykinin (BK) on interleukin (IL)-6 and IL-8 production by human lung fibroblasts. Cells were incubated for $24 \mathrm{~h}$ with a) various concentrations of BK; or b) with $100 \mathrm{nM} \mathrm{BK}$ for the time indicated, and IL- $6(\square)$ and IL-8 $(\diamond)$ were determined by enzyme linked immunosorbent assay in the supernatants. The results are expressed as mean \pm SD of three separate experiments. $*: \mathrm{p}<0.05 ; * *: \mathrm{p}<0.01$. stimulated with $100 \mathrm{nM} \mathrm{BK}$ and cultured for the time indicated, the amounts of IL- 6 and IL- 8 production in response to $\mathrm{BK}$ increased in a time-dependent manner, and reached the maximum at $24 \mathrm{~h}$ (fig. $1 \mathrm{~b}$ ).

Effect of selective bradykinin receptor antagonists on bradykinin-induced interleukin- 6 and -8 production by human lung fibroblasts

It is known that at least two receptor subtypes, B1 and B2, mediate the biological actions of the bradykinin [21]. To characterize the BK receptors involved in BK-induced IL-6 and IL-8 production, the effect of selective B1 and B2 receptor antagonists were examined. B2-receptor antagonist inhibited the production of IL-6 and IL-8 from lung fibroblasts in response to BK (fig. 2). However, B1receptor antagonist did not inhibit the production of IL-6 and IL-8 (fig. 2).

Effect of bradykinin on interleukin-6 and -8 messenger ribonucleic acid expression in human lung fibroblasts

The IL-6 and IL-8 messenger RNA (mRNA) expression of BK-stimulated lung fibroblasts by Northern blot analysis were examined. Unstimulated lung fibroblasts contained trace amount of IL-6 mRNA. However, a significant increase in IL-6 mRNA levels was observed upon stimulation with 1-1000 nM BK (fig. 3). Up-regulation of the IL-6 mRNA levels was detectable $30 \mathrm{~min}$ after BK stimulation, reached the maximum in $1 \mathrm{~h}$, and decreased thereafter. In contrast, unstimulated lung fibroblasts did not contain detectable levels of IL-8 mRNA, with a significant increase in IL-8 mRNA levels upon stimulation with 100-1000 nM BK. Up-regulation of IL-8 mRNA levels was detectable $30 \mathrm{~min}$ after BK stimulation, and reached the maximum in 2-4 h.

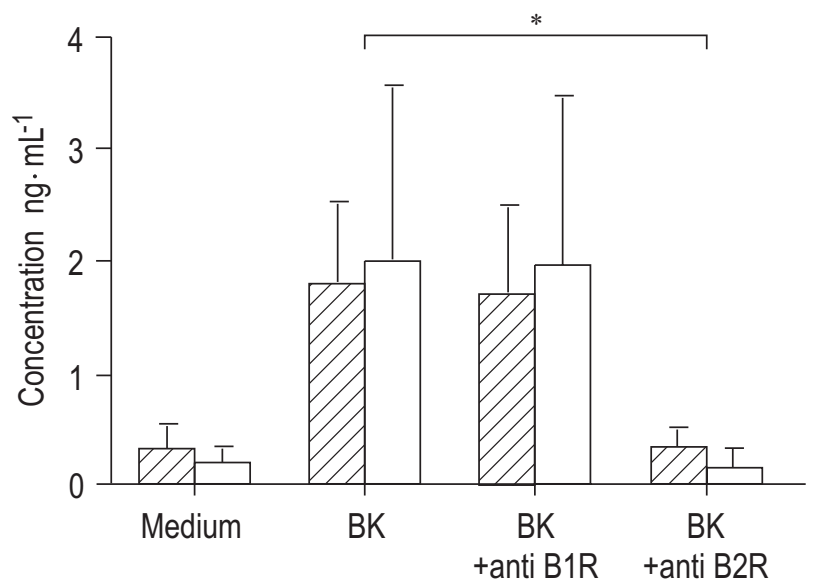

Fig. 2. - Effect of selective bradykinin (BK) receptor antagonists on BK-induced interleukin (IL)- 6 and IL- 8 production by human lung fibroblasts. Cells were incubated with $100 \mathrm{nM}$ BK in the presence or absence of B1 or B2 receptor antagonist for $24 \mathrm{~h}$. IL-6 (ש) and IL-8 ( $\square$ ) were determined by enzyme linked immunosorbent assay (ELISA) in the supernatants. The results are expressed as mean \pm SD of three separate experiments. ${ }^{*}: \mathrm{p}<0.05$. 
a)
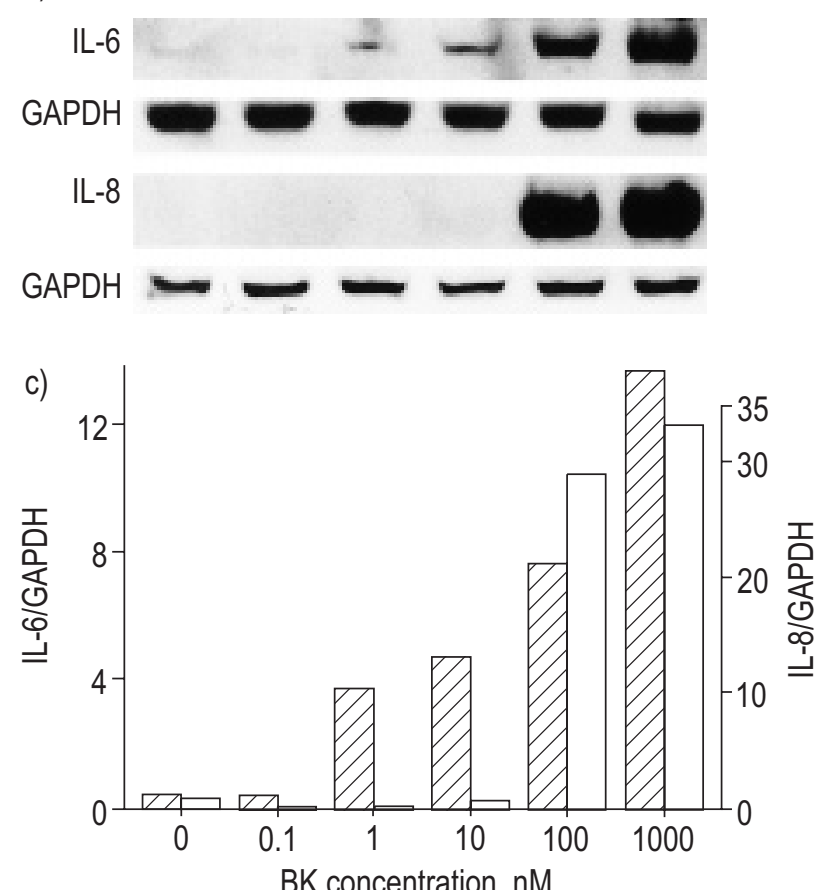

b)

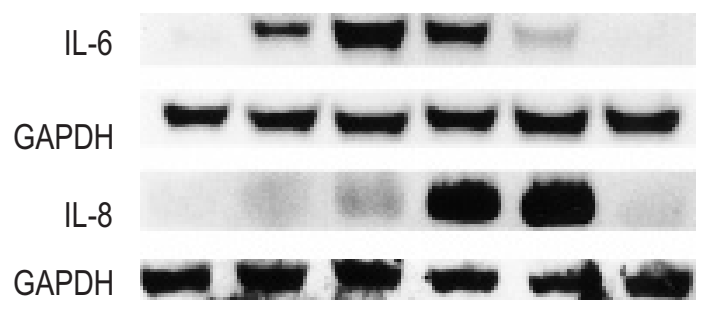

d)

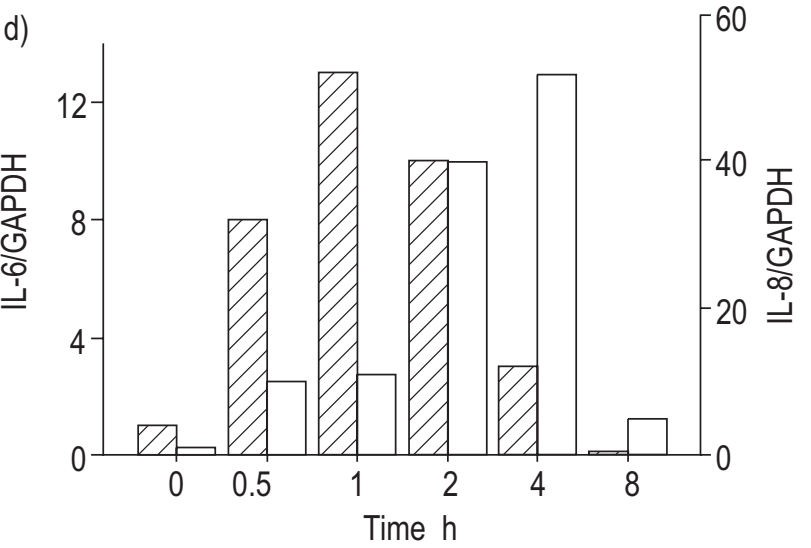

Fig. 3. - Effect of bradykinin (BK) on interleukin (IL)-6 and IL-8 messenger ribonucleic acid (RNA) (mRNA) expression in human lung fibroblasts. $(\mathrm{a}+\mathrm{c})$ Cells were incubated for 2 or $3 \mathrm{~h}$ with various concentrations of BK $(\mathrm{a}+\mathrm{c})$. Total cellular RNA was extracted, and the levels of IL-6 or IL-8 mRNA were evaluated, respectively by Northern blot analysis (a). Densitometric ratios of IL-6 $(\mathbb{Z})$ and IL-8 ( $\square$ ) to reduced glyceraldehyde phosphate dehydrogenase $(\mathrm{GAPDH})$ are shown $\mathrm{c}) . \mathrm{b}+\mathrm{d})$ Cells were incubated with $100 \mathrm{nM}$ BK. At the time indicated total cellular RNA was extracted, and the levels of IL-6 and IL-8 mRNA were evaluated by Northern blot analysis (b). Densitometric ratios of IL-6 (ש) and IL-8 ( $\square$ ) to GAPDH are shown in d). The data shown are representative of three independent experiments.

Extracellular signal-related protein kinase 1/2 involvement in bradykinin-induced interleukin- 6 and -8 production

To identify signalling pathways involved in BK-induced IL-6 and IL-8 production by lung fibroblasts, a role of ERK $1 / 2$ was investigated by Western blot analysis. Lung fibroblasts were treated with $\mathrm{BK}$ for various periods of up to $30 \mathrm{~min}$, and phosphorylation of ERK $1 / 2$ was examined. As shown in figure 4, stimulation of lung fibroblasts with BK rapidly induced phosphorylation of ERK $1 / 2$.

To examine whether the activation of ERK $1 / 2$ is essential for the BK-induced IL-6 and IL-8 production, lung fibroblasts were incubated with $\mathrm{BK}$ in the presence or absence of PD98059, a specific MEK1 inhibitor, for $24 \mathrm{~h}$. As shown in figure 5, PD98059 partially diminished BKinduced IL- 6 and IL-8 production by lung fibroblasts.

\section{p38 mitogen-activated protein kinase involvement in bradykinin-induced interleukin-6 and -8 production}

Since inactivation of ERK $1 / 2$ only partially diminished the BK-induced IL-6 and IL-8 production, a role of p38 MAPK, a member of the MAPK families, was investigated by Western blot analysis. Lung fibroblasts were treated with BK for varying periods of up to $30 \mathrm{~min}$, and phosphorylation of p38 MAPK was examined. As shown in figure 4 , stimulation of lung fibroblasts with BK rapidly induced phosphorylation of $\mathrm{p} 38$ MAPK.
To examine whether the activation of p38 MAPK is required for the BK-induced IL- 6 and IL- 8 production, lung fibroblasts were incubated with $\mathrm{BK}$ in the presence or absence of SB203580, a specific p38 MAPK inhibitor, for $24 \mathrm{~h}$. As shown in figure 5, SB203580 also diminished BK-induced IL- 6 and IL- 8 production by lung fibroblasts.

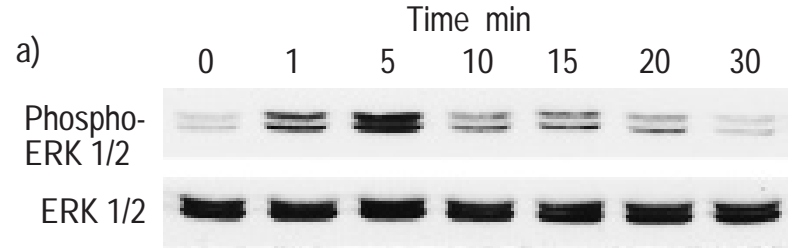

b)

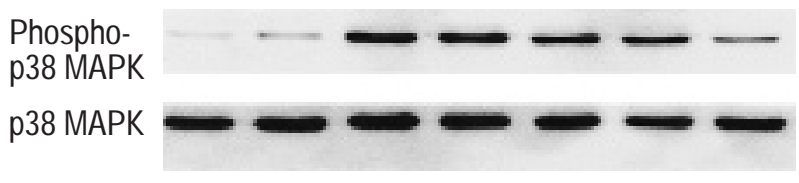

Fig. 4. - Bradykinin (BK)-induced extracellular signal-related protein kinase (ERK $1 / 2$ and p38 mitogen-activated protein kinase (MAPK)) phosphorylation in human lung fibroblasts. Cells were incubated with $100 \mathrm{nM}$ BK for the time indicated. Cell lysates were analysed by SDSPAGE and immunoblotting with a) anti-ERK 1/2 and anti-phospho-ERK $1 / 2$ antibodies; or b) anti-p38 MAPK and anti-phospho-p38 MAPK antibodies. The data shown are representative of three independent experiments. 

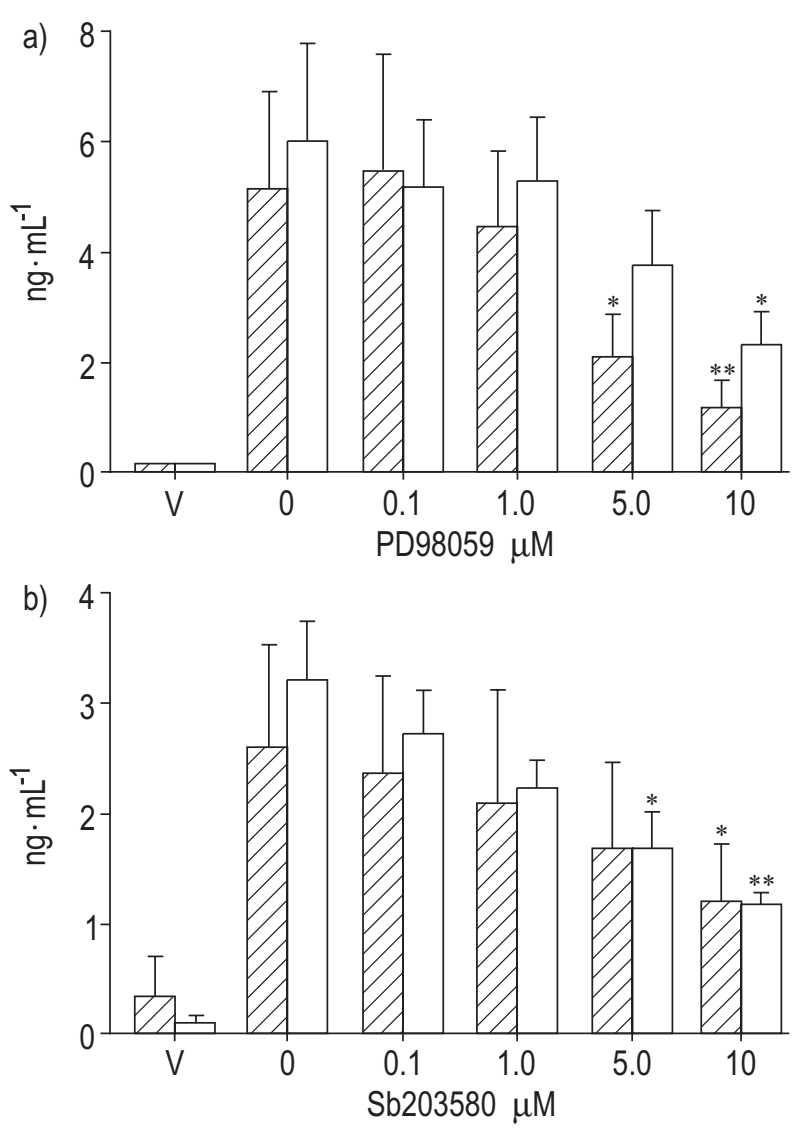

Fig. 5. - Effect of a) PD98059 or b) SB203580 on BK-induced interleukin (IL)- 6 and IL-8 production by human lung fibroblasts. Cells were incubated with vehicle (V) alone or $100 \mathrm{nM} \mathrm{BK}$ in the presence or absence of various concentrations of PD98059 or SB203580 for $24 \mathrm{~h}$. IL-6 (ש) and IL-8 ( $\square$ ) were determined by enzyme linked immunosorbent assay (ELISA) in the supernatants. The results are expressed as mean \pm SD of three separate experiments. ${ }^{*}: \mathrm{p}<0.05 ; * *: \mathrm{p}<0.01$.

The involvement of extracellular signal-related protein kinase 1/2 and p38 mitogen-activated protein kinase in bradykinin-induced interleukin-6 and -8 gene expression

To investigate whether MAPK signalling pathways are involved in BK-induced IL-6 or IL-8 gene expression in lung fibroblasts, the effects of PD98059 and SB203580 were evaluated. As shown in figure 6, these two inhibitors suppressed BK-induced IL-6 and IL-8 mRNA expression in lung fibroblasts.

\section{Discussion}

Bradykinin is thought to be a potent inflammatory mediator involved in acute lung injury, ARDS and systemic inflammatory response syndrome (SIRS) that are associated with conditions such as sepsis, immune-mediated lung injury, and multiple trauma [22, 23]. BK, consisting of nine amino acids, is a major kinin with welldocumented pharmacological properties including vasodilatation and vascular leakage. It enhances production of prostaglandins, leukotrienes, and platelet-activating factor in endothelial cells and fibroblasts [24, 25].

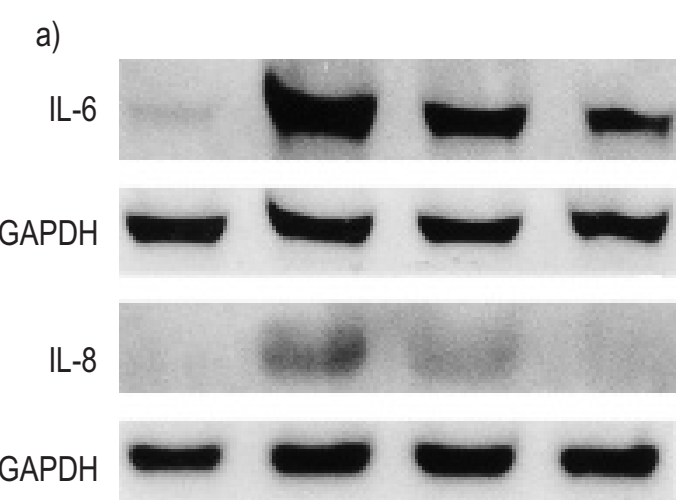

b)

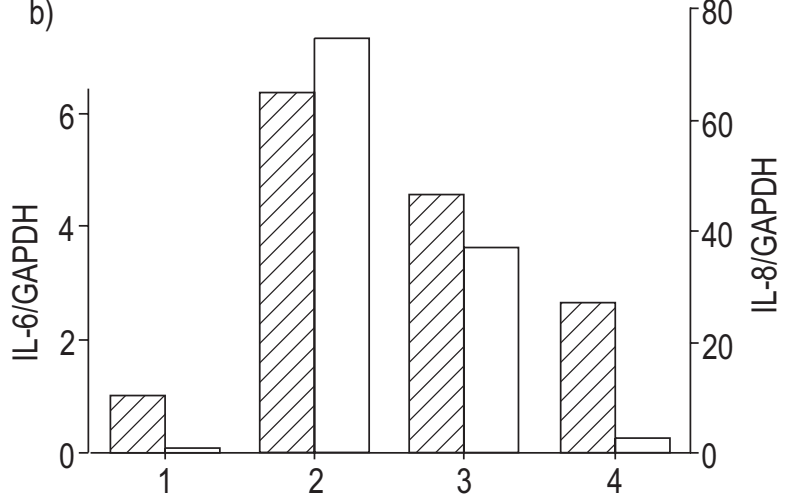

Fig. 6. - Effect of PD98059 or SB203580 on bradykinin (BK)-stimulated interleukin (IL)- 6 and IL-8 gene expression. Cells were incubated with $100 \mathrm{nM}$ BK (track 2), $20 \mu \mathrm{M}$ PD98059 (track 3), $10 \mu \mathrm{M}$ SB203580 (track 4), or diluent alone (track 1 ) for $2 \mathrm{~h}$. Total cellular ribonucleic acid (RNA) was extracted, and the levels of IL-6 and IL-8 messenger RNA were evaluated by Northern blot analysis (a). Densitometric ratios of IL$6(\mathbb{Z})$ or IL-8 $(\square)$ to reduced glyceraldehyde phosphate dehydrogenase (GAPDH) are shown in b). The data shown are representative of three independent experiments.

It has previously been shown that BK stimulated human lung fibroblasts to produce IL- 8 by increasing its gene expression [11]. In the present study, it has been further demonstrated that $\mathrm{BK}$ at $\mathrm{nM}$ concentrations stimulated human lung fibroblasts to produce IL- 6 and IL-8 in a dose- and time-dependent manner. Selective B1 and B2 receptor antagonists were used to show that BK causes IL-6 and IL- 8 production via the B2 receptor. This observation is consistent with the report that the BK-stimulated IL-1 $\beta$ gene expression in human lung fibroblasts can be blocked by a B2 receptor antagonist [13].

It has been reported that BK stimulates ERK $1 / 2$ in mesangial cells [26]. In addition, recent studies have shown that $\mathrm{p} 38$ MAPK regulated IL-8 expression in TNF $\alpha$ - and IL-1 $\alpha$-stimulated pulmonary vascular endothelial cells [27]. However, little is known about the intracellular signal transduction pathway regulating IL-8 expression in BK stimulated human lung fibroblasts. In the present study, it has been demonstrated for the first time that BK treatment enhanced phosphorylation of ERK 1/2 and p38 MAPK in human lung fibroblasts with concomitantly enhanced IL- 6 and IL- 8 protein production, and IL-6 and IL-8 mRNA expression. The present data also showed that MEK1-specific inhibitor PD98059 and p38 MAPKspecific inhibitor SB203580 suppressed IL-6 and IL-8 protein production and their mRNA expression in BK 
stimulated lung fibroblasts. These data suggest that ERK $1 / 2$ and p38 MAPK cascades are involved in BK-induced IL-6 and IL-8 production in human lung fibroblasts.

Since the three classical parallel MAPK cascades are mediated through ERK 1/2, JNK, and p38 MAPK [28], the possibility that the JNK signalling pathway may also be involved in BK-induced IL-6 and IL-8 production in our system cannot be excluded. TuYT et al. [29] showed that okadaic acid-induced IL-6 gene activation in human monocytes appeared to be mediated through activation of the JNK and ERK $1 / 2$ pathways [29]. However, the signalling modules involved in IL-6 and IL-8 gene regulation are not only cell type-specific but also dependent on the stimulatory signal. Further studies are required to elucidate the role of additional MAPK pathways in BK-induced IL-6 and IL-8 gene expression in lung fibroblasts.

The mechanisms of MAPK regulation by BK through $\mathrm{B} 2$ receptor remain to be clarified. Since the B2 receptor is a member of $\mathrm{G}$ protein-coupled receptor family, several steps are involved in the signal transduction leading to MAPK activation [30]. The authors recently reported that the stimulatory effect of BK on IL-8 production by lung fibroblasts is mediated, at least in part, via the PKC dependent pathway [11]. It has been reported that ERK 1/ 2 are enhanced via the PKC activation [31]. These findings are consistent with the idea that BK activates ERK 1/ 2 via the PKC dependent pathway. In contrast, it has been reported that BK-induced nuclear factor- $\mathrm{KB}$ activation and IL- $1 \beta$ synthesis required activation of Rho GTPase [32]. Furthermore, ZANG et al. [33] reported that Rho family GTPases regulate p38 MAPK. Therefore, it is possible that BK-induced phosphorylation of $\mathrm{p} 38$ MAPK may require the activation of Rho GTPase. Further studies are in progress to delineate mechanisms that are involved in BK-induced MAPK activation.

In summary, this study examined the signalling pathways in bradykinin-induced interleukin- 6 and interleukin- 8 production by human lung fibroblasts. The present results demonstrate that: 1) bradykinin significantly stimulated the production of interleukin- 6 and interleukin- 8 by human lung fibroblasts, and the stimulatory effect of bradykinin on interleukin- 6 and interleukin- 8 production was abolished by a selective B2 receptor antagonist; 2) stimulation of lung fibroblasts with bradykinin rapidly induced phosphorylation of extracellular signal-related protein kinase 1/ 2 and p38 mitogen activated protein kinase; and 3) a mitogen activated protein/extracellular signal-related protein kinase 1-specific inhibitor PD98059 and a p38 mitogen activated protein kinase-specific inhibitor SB203580 significantly suppressed bradykinin-induced interleukin- 6 and interleukin-8 production and its gene expression. These data suggest that bradykinin-induced interleukin- 6 and interleukin- 8 production are at least partly mediated through the extracellular signal-related protein kinase $1 / 2$ and p38 mitogen activated protein kinase pathway-dependent activation in human lung fibroblasts and that bradykinin may be involved in the inflammatory reaction leading to acute lung injury through stimulating interleukin-6 and interleukin-8 production by lung fibroblasts.

\footnotetext{
Acknowledgements. The authors wish to thank S. Sugiyama for supplying lung tissues for fibroblasts isolation, and T. Hamazaki for a critical review of the manuscript.
}

\section{References}

1. Traber DL, Redl H, Schlag G, et al. Cardiopulmonary responses to continuous administration of endotoxin. Am J Physiol 1988; 254: H833-H839.

2. Katori M, Majima M, Odoi-Aome R, Sunahara N, Uchida Y. Evidence for the involvement of a plasma kallikreinkinin system in the immediate hypotension produced by endotoxin in anaesthetized rats. Br J Pharmacol 1989; 98: 1383-1391.

3. DeLa Cadena RA, Suffredini AF, et al. Activation of the kallikrein-kinin system after endotoxin administration to normal human volunteers. Blood 1993; 81: 3313-3317.

4. Aasen AO, Smith-Erichsen N, Amundsen E. Plasma kallikrein-kinin system in septicemia. Arch Surg 1983; 118: 343-346.

5. Carvalho AC, DeMarinis S, Scott CF, Silver LD, Schmaier AH, Colman RW. Action of the contact system of plasma proteolysis in the adult respiratory distress syndrome. J Lab Clin Med 1988; 112: 270-277.

6. Wiedemann HP, Matthay MA, Gillis CN. Pulmonary endothelial cell injury and altered lung metabolic function. Early detection of the adult respiratory distress syndrome and possible functional significance. Clin Chest Med 1990; 11: 723-736.

7. Casey L, Krieger B, Kohler J, Rice C, Oparil S, Szidon P. Decreased serum angiotensin converting enzyme in adult respiratory distress syndrome associated with sepsis: a preliminary report. Crit Care Med 1981; 9: 651-654.

8. Roth M, Nauck M, Yousefi S, et al. Platelet-activating factor exerts mitogenic activity and stimulates expression of interleukin 6 and interleukin 8 in human lung fibroblasts via binding to its functional receptor. J Exp Med 1996; 184: 191-201.

9. Elias JA, Lentz V, Cummings PJ. Transforming growth factor- $\beta$ regulation of IL- 6 production by unstimulated and IL-1-stimulated human fibroblasts. J Immunol 1991; 146: 3437-3443.

10. Rolfe MW, Kunkel SL, Standiford TJ, et al. Pulmonary fibroblast expression of interleukin-8: a model for alveolar macrophage-derived cytokine networking. $\mathrm{Am} \mathrm{J}$ Respir Cell Mol Biol 1991; 5: 493-501.

11. Hayashi R, Yamashita N, Matsui S, et al. Bradykinin stimulates interleukin-8 production by human lung fibroblasts. Immunology 1998; 95: 507-511.

12. Paegelow I, Werner H, Vietinghoff G, Wartner U. Release of cytokines from isolated lung strips by bradykinin. Inflamm Res 1995; 44: 306-311.

13. Pan ZK, Zuraw BL, Lung C-C, Prossnitz ER, Browning $\mathrm{DD}$, Ye RD. Bradykinin stimulates NF- $\kappa \mathrm{B}$ activation and interleukin $1 \beta$ gene expression in cultured human fibroblasts. J Clin Invest 1996; 98: 2042-2049.

14. Marshall CJ. Specificity of receptor tyrosine kinase signaling: transient versus sustained extracellular signalregulated kinase activation. Cell 1995; 80: 179-185.

15. Vietor I, Schwenger P, Li W, Schlessinger J, Vilcek J. Tumor necrosis factor-induced activation and increased tyrosine phosphorylation of mitogen-activated protein (MAP) kinase in human fibroblasts. J Biol Chem 1993; 268: 18994-18999.

16. Rawadi G, Ramez V, Lemercier B, Roman-Roman S. Activation of mitogen-activated protein kinase pathways by Mycoplasma fermentans membrane lipoproteins in murine macrophages: involvement in cytokine synthesis. J Immunol 1998; 160: 1330-1339.

17. Kyriakis JM, Banerjee P, Nikolakaki E, et al. The 
stress-activated protein kinase subfamily of c-Jun kinases. Nature 1994; 369: 156-160.

18. Rouse J, Cohen P, Trigon S, et al. A novel kinase cascade triggered by stress and heat shock that stimulates MAPKAP kinase-2 and phosphorylation of the small heat shock proteins. Cell 1994; 78: 1027-1037.

19. Rolfe MW, Kunkel SL, Standiford TJ, et al. Expression and regulation of human pulmonary fibroblast-derived monocyte chemotactic peptide-1. Am J Physiol 1992; 263: L536-L545.

20. Yoshida Y, Maruyama M, Fujita T, et al. Reactive oxygen intermediates stimulate interleukin-6 production in human bronchial epithelial cells. Am J Physiol 1999; 276: L900-L908.

21. Farmer SG, Burch RM. Biochemical and molecular pharmacology of kinin receptors. Annu Rev Pharmacol Toxicol 1992; 32: 511-536.

22. Farmer SG. The kallikrein-kinin system in asthma and acute respiratory distress syndrome. In: Farmer SG, ed. The Kinin System. San Diego, California, Academic Press, 1997; pp. 249-263.

23. Pixley RA, Zellis S, Bankes $\mathrm{P}$, et al. Prognostic value of assessing contact system activation and factor $\mathrm{V}$ in systemic inflammatory response syndrome. Crit Care Med 1995; 23: 41-51.

24. Bhoola KD, Figueroa CD, Worthy K. Bioregulation of kinins: kallikreins, kininogens, and kininases. Pharmacol Rev 1992; 44: 1-80.

25. McIntyre TM, Zimmerman GA, Satoh K, Prescott SM. Cultured endothelial cells synthesize both platelet-activating factor and prostacyclin in response to histamine, bradykinin and adenosine triphosphate. $J$ Clin Invest 1985; 76: 271-280.
26. El-Dahr SS, Dipp S, Baricos WH. Bradykinin stimulates the ERK $\rightarrow$ Elk-1 $\rightarrow$ Fos/AP-1 pathway in mesangial cells. Am J Physiol 1998; 275: F343-F352.

27. Hashimoto S, Matsumoto K, Gon Y, et al. p38 Mitogenactivated protein kinase regulates IL-8 expression in human pulmonary vascular endothelial cells. Eur Respir J 1999; 13: 1357-1364.

28. Su B, Karin M. Mitogen-activated protein kinase cascades and regulation of gene expression. Curr Opin Immunol 1996; 8: 402-411.

29. Tuyt LML, Dokter WHA, Birkenkamp K, et al. Extracellular-regulated kinase $1 / 2$, Jun $\mathrm{N}$-terminal kinase,

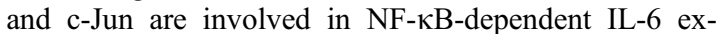
pression in human monocytes. J Immunol 1999; 162: 4893-4902.

30. Gutkind JS. The pathways connecting G protein-coupled receptors to the nucleus through divergent mitogen-activated protein kinase cascades. J Biol Chem 1998; 273 : $1839-1842$.

31. Hoshino M, Izumi T, Shimizu T. Leukotriene D4 activates mitogen-activated protein kinase through a protein kinase Ca-Raf-1-dependent pathway in human monocytic leukemia THP-1 cells. J Biol Chem 1998; 273: 48784882.

32. Pan ZK, Ye RD, Christiansen SC, Jagels MA, Bokoch GM, Zuraw BL. Role of the Rho GTPase in bradykininstimulated nuclear factor- $\kappa \mathrm{B}$ activation and IL-1 $\beta$ gene expression in cultured human epithelial cells. J Immunol 1998; 160: 3038-3045.

33. Zhang S, Han J, Sells MA, et al. Rho family GTPases regulate p38 mitogen-activated protein kinase through the downstream mediator Pak1. J Biol Chem 1995; 270 : 23934-23936. 